\title{
Urgences
}

\section{Leibniz avaleur}

\section{Robert Hébert}

Numéro 15, octobre 1986

Épigraphiques

URI : https://id.erudit.org/iderudit/025324ar

DOI : https://doi.org/10.7202/025324ar

Aller au sommaire du numéro

Éditeur(s)

Urgences

ISSN

0226-9554 (imprimé)

1927-3924 (numérique)

Découvrir la revue

Citer ce document

Hébert, R. (1986). Leibniz avaleur. Urgences, (15), 60-61.

https://doi.org/10.7202/025324ar

Ce document est protégé par la loi sur le droit d'auteur. L'utilisation des services d'Érudit (y compris la reproduction) est assujettie à sa politique d'utilisation que vous pouvez consulter en ligne.

https://apropos.erudit.org/fr/usagers/politique-dutilisation/
Cet article est diffusé et préservé par Érudit.

Érudit est un consortium interuniversitaire sans but lucratif composé de l’Université de Montréal, l'Université Laval et l'Université du Québec à Montréal. Il a pour mission la promotion et la valorisation de la recherche. https://www.erudit.org/fr/ 
Combien d'insectes n'avalons-nous pas sans nous en apercevoir?

G.W. Leibniz: Nouveaux essais surl'entendement humain

Le principe de raison suffisante sonne l'alarme. D'outreManche, un philosophe nommé Locke vient de publier un Essay dont la théorie des passions repose toute sur le mot nouveau uneasiness. Le désir désormais? Un malaise plus ou moins violent pointant le terme de son repos. Tristesse, peur, désespoir de l'inaccessible, colère, envie: inscriptions d'un déplaisir fondamental. Que devient alors l'harmonie décisive des choses si la volonté est déterminée par cette uneasiness radicale, et non plus par l'intimité de son Souverain Bien? Une récompense par la salive? Question capiteuse en Occident, le dialogue s'entame plutôt mal.

Par un coup de génie dont il ignore en l'an 1700 tous les effets, le traducteur français propose inquiétude, italique toujours. Décision "pas facile", traduction imparfaite mais parfaite pour un Leibniz bibliothécaire: ce dernier entend là l'écho moderne d'un mot-cible qui soustrait uneasiness à la pure douleur de la détermination, à sa peau de chagrin faussement mutilée. Il s'emballe, lui-même déjà heurté par le texte-source, heureusement choqué, confirmé: pages aux métaphores vibrantes, poétique souveraine, éclats de l'à-propos qui frise parfois l'incongru, le paléo-surréel. Voilà donc - nous promenant dans la forêt, combien d'insectes n'avalons-nous pas sans nous apercevoir que cela est également nécessaire à la bonne marche de nos connaissances? Tout s'agglutine à la raison de l'inconscient. Écoutez le cumul de l'émotion:... ces "rudiments ou éléments de la douleur ainsi dire ces demi-douleurs"; ... abusons même de ces inaperceptibles aiguilles du désir qui "donne une quantité de demi-plaisirs" que l'amas nuageux métamorphose en continuelle victoire sur soi, ... et sur le prévisible dégoûtant. Ici, le philosophe de Hanovre tremble, sue, en remet dans le microscope. Emboîtement des images et... encore "cette considération de petites aides ou petites délivrances" qui n'en finit pas. Combien de colonies d'insectes travaillent ainsi les "petites sollicitations imperceptibles" qui par habitude de l'inquiétude tiennent en haleine et en vie l'économie de la machine? Vingt fois, le subliminal est convoqué: nous ne savons pas ce qui nous manque, semble-t-il, mais le corps seul inspire à tous les jours ce que nous 
demandons pour le savoir.

Le temps interrompt bientôt le monologue postal, mort de Locke en 1704. Leibniz dépose son texte dans le tiroir. Après un demi-siècle de sommeil et quelques guerres d'empires, les mécanismes créateurs de la pensée se manifestent dans la plus étrange rencontre de la modernité. Dialogue fictif à travers l'alarme et la politesse, appropriation dévorante d'autrui sur la presqu'île de l'essai. Une écriture du tic au tac, elle-même étalée, étalant comme un tue-mouches, se permettant à la fin de prendre l'air, marcher à l'infini, faire une promenade jusqu'au "bout de l'allée" et, quant au choix viscéral, se tourner vers oũ? Simple comme bonjour. Uneasiness au coeur de l'automate souverain, traduisant et cédant alors le pas à l'allemand Unruhe, le balancier inquiet, nerveux mais confiant de l'horloge. Tout se comprend. Tout est victoire sur le semblant des contraires. Déplaisirs contre plaisir? Vraiment ou vice-versa? Les "petits ressorts" de l'inconscient confirmeront toujours le meilleur homéostat des mondes possibles. 